\title{
REVIEW
}

\section{COVID-19, ENVIRONMENT, CLINICOPATHOLOGIC FEATURES, LABORATORY FINDINGS AND DIAGNOSIS, TREATMENT, VACCINES, ANIMALS, AND CANCER}

\author{
A. Amirkhani Namagerdi ${ }^{1}$, F. Ciani ${ }^{1}$, D. d'Angelo ${ }^{1}$, L. Carangelo² ${ }^{2}$ F. Napolitano ${ }^{1,3}$, \\ L. Avallone ${ }^{1}$ \\ ${ }^{1}$ Department of Veterinary Medicine and Animal Production, University of Naples Federico II, Naples, Italy \\ ${ }^{2}$ Centro di Farmacovigilanza e di Farmacoepidemiologia di rilevanza regionale della regione Campania, Università \\ degli studi della Campania Luigi Vanvitelli \\ ${ }^{3}$ CEINGE - Biotecnologie Avanzate, Naples, Italy
}

\section{CORRESPONDING AUTHOR:}

Francesca Ciani

Department of Veterinary Medicine and Animal Production

University of Naples Federico II

via F. Delpino 1

80137 Naples, Italy

E-mail: ciani@unina.it

ORCID: 0000-0002-9188-6761

Doi: $10.48286 / a r o .2022 .40$

\section{ABSTRACT}

SARS-CoV-2 (COVID-19) belongs to the same coronavirus group (Beta-coronavirus) as SARS and MERS viruses that caused two of the more severe epidemics in recent years. Horseshoe bats (genus Rhinolophus) have been identified as the natural reservoirs of SARS-related coronaviruses (CoVs) and the likely origin of SARS-CoV-2. The intermediate host is thought to be the pangolin. The purpose of this review is to draw attention to the relationship between COVID-19 and different malignancies, and to discuss the similarities in their pathogenesis, and the possible repurposing of cancer drugs for the treatment of

\section{KEY WORDS}

COVID-19; SARS-CoV-2; cancer; environment; animals.
COVID-19. Along with antiviral and anti-inflammatory drugs, several anti-cancer drugs can be potentially repurposed in the management of COVID-19. The pathogenesis of COVID-19 and cancer shares certain similarities, including inflammation, immunological dysregulation, and coagulopathy. Blood parameters in COVID-19 patients upon admission show lymphocytopenia, and elevated C-reactive protein (CRP), ferritin, lactate dehydrogenase (LDH), and D-dimer levels in most of the patients. Currently, RT-PCR is the gold-standard laboratory test for COVID-19 confirmation in suspected cases.

\section{IMPACT STATEMENT}

This review wants to address some aspects of COVID-19, such as environment, pathophysiology, laboratory findings, diagnosis, therapeutic and preventive treatment, role of different animals in transmission, with particular attention to cancer. 


\section{INTRODUCTION}

Coronaviruses are members of the Coronaviridae family in the Nidovirales order. The coronavirus family is divided into four subgroups: alpha $(\alpha)$, beta $(\beta)$, gamma $(y)$, and delta $(\delta)$. Alpha- and beta-coronaviruses are found in mammals, particularly bats, while gamma- and delta-coronaviruses are found in pigs and birds (1). SARS-CoV-2 is a member of the same coronavirus family (Betacoronavirus) as the SARS and MERS viruses, which were responsible for two of the most devastating epidemics in recent years (2). Horseshoe bats (genus Rhinolophus) were discovered to be natural reservoirs of SARS-related CoVs and the likely source of SARSCoV. Fruit bats (Rousettus aegypticus) can become infected and transfer the disease to other bats (3). Malayan pangolins have also been shown to have closely similar sequences (4). The inclusion of an intermediary, such as the pangolin, is suggested by the fact that SARS-CoV-2 was initially detected in Wuhan, China, far from where the horseshoe bat is found (5). These are enveloped viruses. The capsid is made up of the nucleocapsid protein $\mathrm{N}$, which is surrounded by a membrane composed of three proteins: the membrane protein $(\mathrm{M})$, the envelope protein $(E)$, which are involved in the virus budding process, and the spike glycoprotein (S) (6). The SARS-CoV-2 virus is $50-200 \mathrm{~nm}$ in diameter and contains a + ssRNA genome of approximately 29.9 $\mathrm{kb}$ in length, making it the biggest known RNA virus. It has a 5'-cap structure and a 3'-poly-A-tail, and 14 putative open reading frames (ORFs) encoding 27 proteins (7). The SARS-CoV-2 genome has ten genes. The genes are organized in the following order: 50-replicase-S-E-M-N-30, with genes for accessory proteins inserted among structural genes $(\mathrm{S}, \mathrm{E}, \mathrm{M}, \mathrm{N})$. The polymerase gene, which has two overlapping open reading frames (ORFs), figures $\boldsymbol{1} \boldsymbol{a}$ and $\boldsymbol{b}$, takes up around two-thirds of the total RNA(8). SARS-CoV-2 uses ACE2 as an attachment receptor and TMPRSS2 for spike protein priming, membrane fusion, and cell entry. TMPRSS2 cleaves ACE2 at Arginine 697-716 (9). The ACE2 gene is an escape gene that is found in the Xp22.2 region of the $X$ chromosome. In principle, females get a double dose of ACE2, which might compensate for the loss of membrane ACE2 caused by SARS-CoV-2 (10). (figures $1 \boldsymbol{a}, \boldsymbol{b}$ ).

Quite recently, due to its importance, considerable attention has been paid to, and many publications have been released about the different features of COVID-19. The purpose of this review is to draw attention to the relationship between COVID-19 and different malignancies, and to discuss the similarities in their pathogenesis, and the possible repurposing of cancer drugs for the treatment of COVID-19. The remainder of the paper is organized into ten sections, starting with Section II, which discusses the role of the environment, and ending with Section X, which is devoted to cancer.

\section{COVID-19 AND ENVIRONMENT}

The origins of emerging infectious diseases (EIDs) are strongly linked to socioeconomic, environmental, and ecological factors. Changes in the manner and intensity of land use around the world are creating more dangerous interfaces between people, animals, and wildlife, which are a zoonotic disease reservoir (12). Because of the loss of habitat, animals are forced to move, where they may come into touch with other animals or people and spread germs (13). Humans and cattle are more likely to come into touch with wildlife, particularly in regions where forest cover has been reduced by more than 25\% (14). Pathogen transmission from wild animals to domestic animals and humans, and vice versa, has resulted in major epidemics and pandemics around the world (14). Large livestock farms can also serve as a source for spillover of infections from animals to people (13). People are infected directly or indirectly by zoonotic viruses when they touch live primates, bats, and other wildlife (or their meat) or farm animals such as chickens and pigs (15). Live and dead wild animals come into contact with hunters, traders, customers, and everyone else involved in the wildlife trade at wildlife markets and in the legitimate and criminal wildlife trade (15). Air pollution, particularly NO2 and PM2.5 (particles with a diameter of less than 2.5 micrometers), may increase the susceptibility to infection and mortality from COVID-19 (16). PM2.5 and NO2 have a strong relationship with COVID-19 (17). Climate change is caused by carbon dioxide (CO2) emissions. Pandemic risk is increased by several of the core causes of climate change. For centuries, carbon dioxide persists in the atmosphere and oceans. $\mathrm{CO} 2$ emissions have fallen globally owing to coronavirus lockdown. According to scientists, this will be the largest reduction in manmade $\mathrm{CO} 2$ emissions since World War-I 

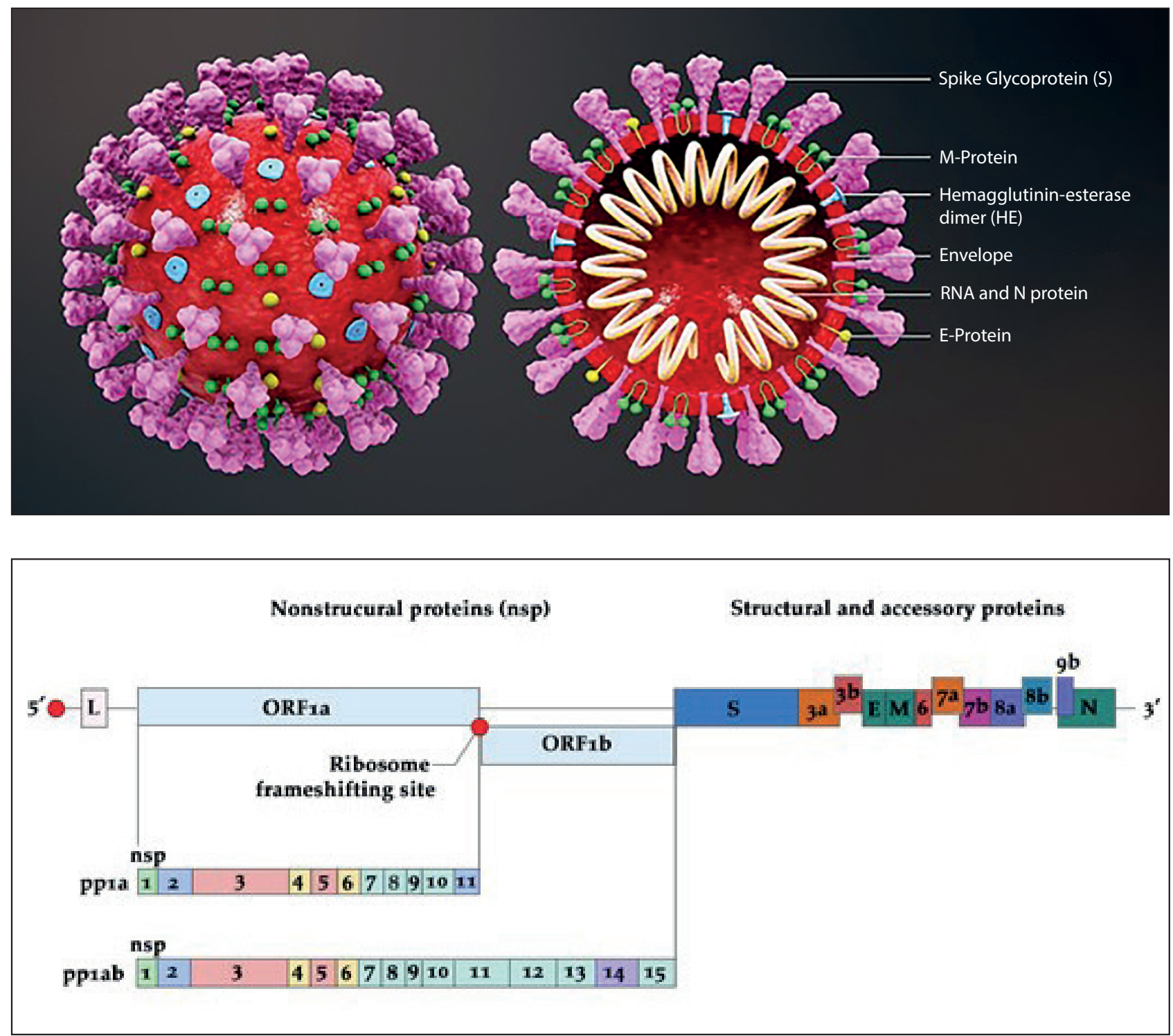

Figures $1 \boldsymbol{a}$. Schematic presentation of the SARS-CoV-2; $\boldsymbol{b}$. its genome structure. SARS-CoV-2 has a spherical structure. The virus has an outer lipid envelope, covered with spike glycoprotein. The RNA genome has a replicase complex (comprised of ORF1a and ORF1b) at the 5'UTR. The ORF1 a encodes for nsp1-nsp11, while ORF1b encodes for nsp1-nsp15. Four genes that encode for the Structural proteins: Spike gene, Envelope gene, Membrane gene, Nucleocapsid gene and a poly (A) tail at the $3^{\prime} U T R$. The accessory genes are distributed in between the structural genes. (a: credit to https://www.scientificanimations.com/wiki-images/; b: modified from (11)).

(18). According to NASA researchers, ozone concentrations above the polar parts of the planet declined by roughly 240 Dobson units on March 12, 2020, compared to March 12, 2019. Low levels like these are extremely unusual, occurring just once every ten years or so (19).

\section{PATHOPHYSIOLOGY}

The spike glycoprotein-S enhances the virus's attachment to the angiotensin-converting enzyme 2 (ACE2) receptor and allows it to fuse with the host cell's membrane (7). There are two functional subunits in the $\mathrm{S}$ glycoprotein. The S1 subunit, which contains the RBD, is important for binding to the host cell receptor, while the S2 subunit is important for fusing of the viral and cellular membranes (20). SARS-CoV-2 then infects target cells by using serine proteases TMPRSS2 (transmembrane protease serine 2) for S protein priming (7). This protein is used for cell entrance by the influenza virus and the human coronaviruses HCoV-229E, MERS-COV, SARS-CoV, and SARS-CoV-2 (COVID-19 virus) (21). Type 2 alveolar cells, nasal goblet cells, nasal ciliated cells, corneal cells, and intestinal epithelial cells are all likely SARS-CoV-2 host cells since they show high amounts of both ACE2 and TMPRSS2. SARS-CoV-2 appears to infect mononuclear phagocytes but not lymphocytes among 
immune cells (22). SARS-CoV-2 infects pulmonary capillary endothelial cells in addition to epithelial cells, amplifying the inflammatory response and triggering an influx of monocytes and neutrophils (23). $15-30 \%$ of persons who are hospitalized with COVID-19 will develop COVID-19-associated acute respiratory distress syndrome (ARDS) (24). Patients with COVID-19-related ARDS who have decreased respiratory system compliance and elevated D-dimer concentrations have a high death risk (25). Two genetic susceptibility loci at Chr3p21.31 and Chr9q34.2 were discovered in the first genome-wide association study (GWAS) of severe COVID-19 with ARDS. The locus Chr3p21.31 spans the genes SLC6A20, LZTFL1, CCR9, FYCO1, CXCR6, XCR1, CCR1, and include several chemokine receptors (CCRs, CXCR6, and XCR1) that mediate chemokine signaling pathways for leukocyte chemotaxis and cause lung injury (26). The presence of high levels of ACE2 in the intestine makes the small bowel and colon particularly vulnerable to SARS-CoV-2 infection. According to the Human Protein Atlas database, the expression of ACE2 messenger RNA and protein in the gut is 100 times higher than in the lung (27). SARS-CoV-2 is largely spread from person to person through close contact (about $2 \mathrm{~m}$ ) and aerosol respiratory droplets with a diameter of less than $5 \mu \mathrm{m}$ in diameter (17). Longer exposure to an infected person (at least 15 minutes within 6 feet) and shorter exposures to symptomatic individuals are linked to a higher probability of transmission (28). Both TMPRSS2 and ACE2 are found in human corneal epithelial cells, implying that ocular surface cells could be viral entry sites as well (29). Another mechanism of transmission is contact surface spread. Aerosols may also be a cause of infection in humans outside of a laboratory setting, however it is unknown if this is a substantial cause of infection in humans (28). Viral shedding can begin 5 to 6 days before the first symptoms occur, and infectiousness can drop dramatically 8 days after the first symptoms occur (30). The median incubation period was calculated to be 5.1 days among 181 confirmed cases with known exposure and symptom start dates, and 97.5 percent of those who develop symptoms go through with within 11.5 days following infection (31). The most prevalent symptoms in hospitalized patients are fever (up to $90 \%$ of patients), dry cough (60\%-86\%), shortness of breath (53\%$80 \%)$, fatigue (38\%), nausea/vomiting or diarrhea (15\%-39\%), and myalgia (15\%-44\%). Non-classical symptoms, such as isolated gastrointestinal complaints, can also be present. In $64 \%$ to 80 of patients, olfactory and gustatory dysfunctions have been recorded (28). The underlying pathophysiology of the loss of these olfactory and gustatory perceptions has been linked to direct damage to the olfactory epithelium's supporting cells, the olfactory bulb, and altered olfactory neuron function, altered ACE2 signal transmission, and intensified gustatory particle degradation by sialic acid (32). Hypertension (56.6\%), obesity (41.7\%), and diabetes (33.8\%) were the most common comorbidities in 5700 hospitalized patients, according to clinical research (33). Acute renal injury (9\%), liver dysfunction (19\%), bleeding and coagulation dysfunction (10\%-25\%), and septic shock (6\%) are all possible complications for hospitalized patients (28). It is unclear why children are less likely to contract COVID-19. The following are some possible explanations: Children's immune responses are less vigorous (no cytokine storm), they have partial immunity from prior viral exposures, and they have lower rates of SARS-CoV-2 exposure. SARS-CoV-2 infection has recently been linked to a rare multisystem inflammatory illness similar to Kawasaki disease in children in Europe and North America (34). RNA viruses have a higher rate of mutation than DNA viruses. Coronaviruses, on the other hand, create fewer mutations than most RNA viruses because they encode an enzyme that corrects some replication errors (34). In the global pandemic, a SARS-CoV-2 variant with the Spike protein amino acid mutation D614G has become the most common type. The transition from D614 to G614 happened asynchronously in different parts of the world, starting with Europe, then North America and Oceania, and finally Asia (35). This dominant strain is ten times more infectious than Wuhan-1 strain. In both Denmark and the Netherlands, a mink-related variation Y453F has been discovered (36). Y453F is found in the RBD and is most likely a mink ACE2 adaptation, but it also boosts affinity for human ACE2 and replicates as well as the wildtype (37). In the United Kingdom, a SARS-CoV-2 variant B1.1.7 with a mutation $\Delta 69 / 70$ has spread fast (38). This variant accounted for around $28 \%$ of SARS-CoV-2 infection cases in England as of December 28, 2020, and population genetic models imply it is spreading 56 percent faster than other lineages (34). The E484K mutation can be found in different variants including, the South African (B.1.351), Brazilian (B.1.1.28), and UK B.1.1.7 var- 
iants (39). The SARS-CoV-2 B.1.617 lineage was identified in October 2020 in India (40). The lineage includes three main subtypes (B1.617.1, B.1.617.2 and B.1.617.3), harbouring diverse Spike mutations in the N-terminal domain (NTD) and the receptor binding domain (RBD) which may increase their immune evasion potential. B.1.617.2, also termed variant Delta, is believed to spread faster than other variants. Sera from individuals having received one dose of Pfizer or AstraZeneca vaccines barely inhibited variant Delta. Administration of two doses generated a neutralizing response in $95 \%$ of individuals, with titers 3 to 5 fold lower against Delta than Alpha(B.1.1.7) (41). The Lambda (C.37) lineage was classified as a variant of interest (VOI) by the World Health Organization on June $15^{\text {th }}, 2021$. The $C .37$ variant, which lies within the B.1.1.1 lineage, has already been reported as highly prevalent in Peru and has also been identified in many countries across the Americas, Europe and Oceania (42). The Omicron variant, also known as B.1.1.529, is a novel extensively mutated SARSCOV2 variant that was identified as a variant of concern (VOC) by the World Health Organization on November 26, 2021 (43).

\section{LABORATORY FINDINGS}

The average range of laboratory abnormalities identified in COVID-19, according to a systematic evaluation of 19 studies involving 2874 patients included elevated serum C-reactive protein (increased in $>60 \%$ of patients), LDH (increased in approximately 50\%-60\%), alanine aminotransferase (elevated in approximately 25\%), and aspartate aminotransferase (approximately 33\%) (28). According to Huang et al. (44) a serum albumin level of $<35 \mathrm{~g} / \mathrm{L}$ at presentation increased the risk of death in COVID19 by at least 6 times. According to Khourssaji et al. (45), blood parameters in COVID-19 patients upon admission indicated elevated C-reactive protein (CRP) (100\%), ferritin (92\%), LDH (80\%), white blood cell (WBC) count (26\%) with lymphocytopenia (52\%) and eosinopenia (98\%). Yao et al. (46) showed that D-dimer elevation ( $\geq 0.50 \mathrm{mg} / \mathrm{L}$ ) was found in $74.6 \%(185 / 248)$ of the patients, and D-dimer level of $>2.14 \mathrm{mg} / \mathrm{L}$ predicted in-hospital mortality with a sensitivity of $88.2 \%$ and specificity of $71.3 \%$. Al-Samkari et al. (47) described that in a multicenter retrospective study of 400 hospital-admitted COVID-19 patients, additional markers at initial presentation predictive of thrombosis during hospitalization included platelet count $>450 \times 109 / \mathrm{L}, \mathrm{CRP}>100 \mathrm{mg} / \mathrm{L}$, and erythrocyte sedimentation rate (ESR) $>40 \mathrm{~mm} / \mathrm{h}$. COVID-19-associated coagulopathy (CAC) has characteristics that are unique from bacterial sepsis-induced coagulopathy (SIC) and disseminated intravascular coagulation (DIC) (48). COVID-19-induced coagulopathy $(\mathrm{CIC})$ is characterized by a significant increase in D-dimer and fibrin split products but little or no change in activated partial thromboplastin time and prothrombin time upon presentation (49). Neutrophil extracellular traps (NETs), including cell-free DNA, are higher in severe COVID-19 patients requiring mechanical ventilation, according to Zuo et al. (50), and have a substantial correlation with acute phase reactants such as CRP, D-dimer, and LDH. These NETs have the capacity to spread inflammation and microvascular thrombosis. The occurrence of the virus-induced "cytokine storm" has been related to mortality in COVID-19 patients (51). Guo et al. (52) showed that, D-dimer rises before the cytokine storm reflected by the IL-6 rise, implying that coagulopathy could operate as a signal to intensify a cytokine storm. COVID-19 infection appears to cause a worse cytokine storm, culminating in widespread micro- and macrovascular thrombosis and organ failure (49). Calprotectin, CRP, IL-1, IL-10, and tumor necrosis factor (TNF-) are all up to 200-fold higher than normal, while IL- 6 can be up to 1000 -fold higher than normal in recorded cases (26). In the event of SARSCoV-2, higher innate immune system cytokine levels, such as IL-8 and IL18, are linked to greater severity in men. Females, on the other hand, had a lower severity in line with a larger T-cell activation (10). Within 3 weeks of the onset of symptoms, patients with Covid-19 develop kidney dysfunction, primarily acute kidney injury (AKI), hematuria, and proteinuria. The pathogenesis of AKI can be linked to COVID-specific mechanisms (direct viral entry, unbalanced RAS activation, virally induced proinflammatory cytokines, and thrombotic state) as well as nonspecific pathways (right heart failure, hypovolemia, nosocomial sepsis, nephrotoxic drugs, high PEEP in cases demanding mechanical ventilation and hemodynamic changes) (53). The GI signs seen in COVID-19 are caused by SARSCoV-2 infection of intestinal enterocytes, which leads to ileum and colon dysfunction. According to multiple studies, people with severe COVID-19 have increased liver enzymes and a higher rate of 
liver injury. Patients with abnormal liver function tests, particularly raised alanine aminotransferase (ALT) and aspartate aminotransferase (AST), were also more likely to develop severe pneumonia (54). Wang et al. (55) found that, the rate of pancreatic damage was not actually low (17\%) among the 52 patients with COVID-19 pneumonia. COVID-19 appears to exacerbate diabetic problems, most likely due to viral-induced pancreatic dysfunction, along with immunological dysregulation, vasculopathy, and coagulopathy (56).

\section{DIAGNOSIS}

Antibody tests use lateral flow assays to quickly identify antigens (spike, membrane, or nucleocapsid proteins) or antibodies for COVID-19. Rapid diagnostic tests (RDT), enzyme-linked immunosorbent assays (ELISA), neutralization assays, and chemiluminescent immunoassays are the four main types of antibody tests (57). The companies have centered their efforts on developing ELISA kits for detecting serum antibodies against two $\mathrm{S}$ protein domains (S1 and S2). In detecting antibodies from mildly infected COVID-19 patients, the RBD and N ELISA tests were found to be more sensitive than the S1 ELISA test (58). When compared to other testing methods, molecular diagnostic procedures are more appropriate since they target the pathogen's genome or proteome, making them more specific and precise (59). Currently, the gold-standard laboratory test for COVID-19 confirmation in suspected patients is RT-PCR (60). Eight of 13 studies evaluating SARS-CoV-2 viral load in serial upper respiratory tract samples showed peak viral loads calculated based on cycle threshold values within the first week of symptom onset (61). Among 1070 specimens collected from 205 patients with COVID-19, bronchoalveolar lavage fluid specimens showed the highest positive rates (14 of $15 ; 93 \%$ ) by RT-qPCR testing followed by sputum (72 of 104; 72\%), nasal swabs (5 of 8 ; $63 \%$ ), fibro-bronchoscope brush biopsy (6 of 13; $46 \%)$, pharyngeal swabs (126 of 398; 32\%), feces (44 of 153; $29 \%$ ), and blood (3 of 307; 1\%). None of the 72 urine specimens tested positive (62). Droplet digital PCR (ddPCR) is the most extensively utilized method among different partitioning methods (microwell plates, capillaries, oil emulsion, miniaturized chambers) (63). In the detection of low-viral load samples, digital PCR (dPCR) sur- passes RT-qPCR and can be used as a complement (64). Notomi et al. ${ }^{65}$ created a new method called loop-mediated isothermal amplification (LAMP) in the year 2000, which amplifies DNA with high specificity, efficiency, and rate under isothermal conditions. They used a DNA polymerase and a set of four specially designed primers that recognize a total of six distinct sequences on the target DNA. Rabe et al. (66) recently established a sensitive (RT-LAMP) assay compatible with current reagents that used a colorimetric readout in as fast as 30 minutes for SARS-CoV-2 detection. Lau et al. (67) designed and optimized a sensitive reverse transcription recombinase polymerase amplification assay (RT-RPA) for the fast detection of SARSCoV-2 utilizing SYBR Green I and/or lateral flow (LF) strips. In experimental systems, four classes of Clustered regularly interspaced short palindromic repeats (CRISPR)-derived genome editing agents are currently available: nucleases, base editors, transposases/recombinases, and prime editors (68). Cas12a (CRISPR-associated protein 12a) or Cas13a (CRISPR-associated protein 13a) nucleases are used in the most innovative forms of these researches that take advantage of collateral cleavage of single-stranded DNA (Cas12a) or RNA (Cas13a) (63). Broughton et al. (69) used the Cas12a method for COVID-19 diagnosis. The assay was created to detect regions in the SARS-CoV-2 $\mathrm{E}$ and $\mathrm{N}$ genes, and the human RNase $P$ gene as a control (63). the SHERLOCK (specific high-sensitivity enzymatic reporter unlocking) COVID-19 detection methodology based on CRISPR-Cas13 screens for unique nucleic acid targets (SARS-CoV-2 ORF1 $1 \mathrm{ab}$ and S genes) and employs a dipstick as a visual readout in less than an hour. Other molecular methods, like microarray assays and viral sequencing (next-generation sequencing) can be utilized for the detection of SARS-CoV-2, however, their application is still restricted (58) (figure 2 ).

\section{PATHOLOGICAL FEATURES}

The main target organ of COVID-19 is the lung. The pathological features of COVID-19 are comparable to those of Middle Eastern respiratory syndrome (MERS) coronavirus infection and SARS (70). The lungs are heavy and congested with bilateral interstitial edema. Grossly visible pulmonary emboli and a distinctive patchy gross appearance of the lung parenchyma have been reported (71). 


\section{APPROVED DIAGNOSTIC METHODS}

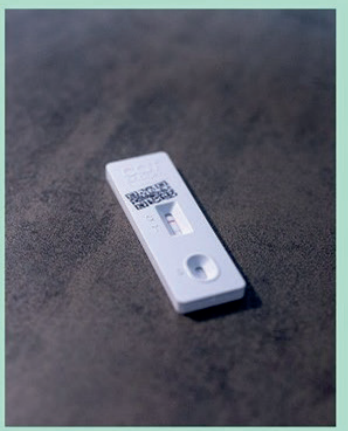

Rapid antigen and rapid antibody tests

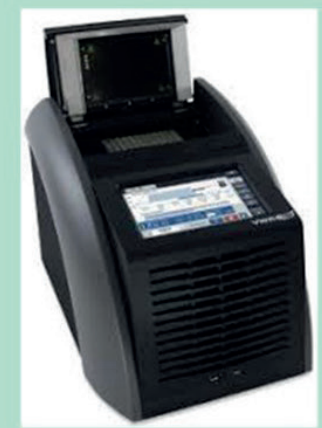

R T - P C R - b a s e d molecular tests

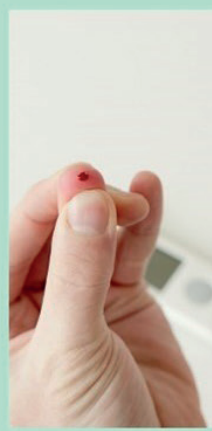

I m m un e enzy matic serological tes $\mathrm{ts}$

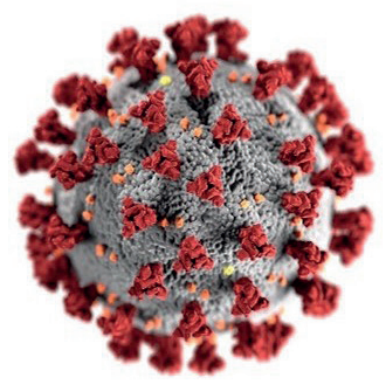

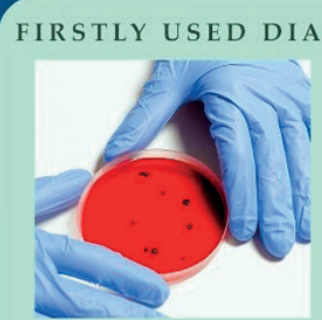

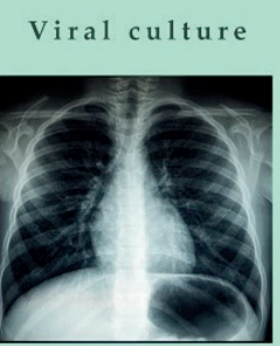

Radiological investigations

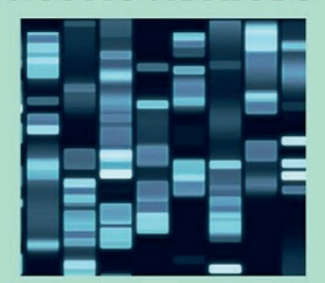

Next generation sequencing (NGS)

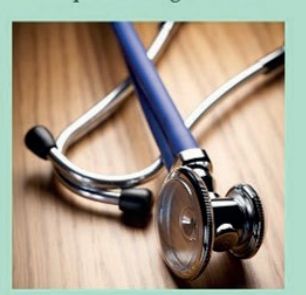

Clinical examinations

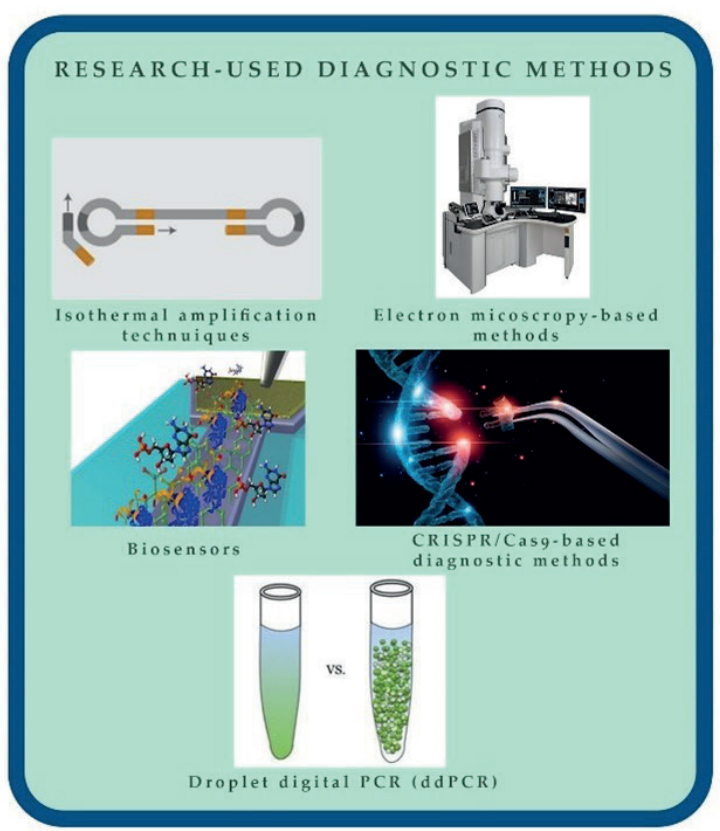

Figure 2. Overview of the available clinical, diagnostic and research strategies for the effective diagnosis of COVID19 infection.

Elsoukkary et al. (72) showed that the average total lung weight was $1,851 \mathrm{~g}$ (reference range $=685-1,050 \mathrm{~g}$ ) in a postmortem study on $32 \mathrm{pa}$ tients with COVID-19. Exudative and proliferative diffuse alveolar damage (DAD) were present in most of the patients $(n=24,75 \%)$. The acute stage of DAD, as in other conditions, is marked by the presence of hyaline membranes, while the organ- 
izing phase is characterized by variable degrees of the proliferation of fibroblasts and myofibroblasts (73). Pronounced fibroblastic proliferation, partial fibrosis, pneumocyte hyperplasia leading to interstitial thickening and collapsed alveoli, and patchy lymphocyte infiltration were the predominant findings in 10 confirmed cases of COVID-19 in the organizing-stage diffuse alveolar damage according to Schaller et al. (74). In areas with organized diffuse alveolar damage, reactive osseous and squamous metaplasia were seen (74). Xiao et al. (75) performed gastrointestinal endoscopy for a confirmed COVID-19 patient. Histological examination revealed damage to the mucosa in esophagus, and infiltration of numerous plasma cells and lymphocytes in the lamina propria of the stomach, duodenum, and rectum. The cytoplasm of gastric, duodenum, and rectal glandular epithelial cells were marked with viral nucleocapsid protein, but not in the esophageal epithelium, since ACE2 is rarely expressed in the esophageal epithelium. Lagana et al. (76) examined the liver sections of 40 COVID-19 autopsies. Grossly, two livers showed fibrosis and one had abscesses, the remaining livers showed varying degrees of steatosis, congestion, and ischemia. The most common histological findings were, macrovesicular steatosis, mild acute hepatitis, and minimal-to-mild portal inflammation. Santoriello et al. (77) showed that, acute tubular injury (ATI) was the most notable renal histologic finding in a group of 42 autopsied patients dying with COVID-19. The degree of ATI was most commonly mild, and ischemia, hypoxia, sepsis-associated factors, and toxin exposure could be suggested as the etiologic factors. Giavedoni et al. (78) showed that COVID-19 related cutaneous lesions could be classified into six patterns: Generalized maculopapular (20.7\%), Grover's disease and other papulovesicular eruptions (13.8\%), livedo Reticularis (6.9\%), Other eruptions (22.4\%), Urticarial (6.9\%), and CHilblain-like (29.3\%). In acral chilblain-like lesions, a diffuse heavy lymphoid infiltrate of the dermis, and the hypodermis, with a predominant perivascular pattern are seen (79). Fox et al. (80) detected the major gross and microscopic findings of 22 hearts from COVID-19 infection confirmed deaths. The hearts weighed 340-1010 gm. The most significant finding was severe right ventricular dilatation. Marked diffuse single myocyte necrosis was seen on microscopic examination. The endothelial cells of the small arterioles, venules, and capillaries were plump, and immunostaining showed diffuse perivascular infiltration of CD4 and CD8 lymphocytes. Lymphocytopenia, neutrophilia, eosinopenia, mild thrombocytopenia, and less frequently, thrombocytosis (81) are the most frequent hematological findings. Lymphocytopenia appears to be the most important change in the peripheral blood, and it can be used as a marker of severity of the infection (82). Harris et al. (83) investigated the bone marrow of 19 autopsied cases. They were all normocellular to hypercellular, with a myeloid shift, and hemophagocytic histiocytes were detected. Xu et al. (84) performed postmortem needle biopsies from the spleen on 10 patients who died from COVID-19 in Wuhan. The histopathological examination showed decreased cellularity of the spleen with atrophic white pulps at various ranges. The lymphoid follicles were diminished or nonexistent at all, and the ratio of red pulp to white pulp was variably increased. Liu et al. (85) noticed that the 12 postmortem spleens were all contracted and had shrinking capsules. The contracted spleens showed, mixed thrombi, anemic infarction, and hemorrhagic areas. Bryce et al. (86) studied the microscopic findings of the thoracic lymph nodes of 60 cases. Sinus histiocytosis was detected in 50 cases, 34 of which showed foci of hemophagocytosis. Germinal centers were lacking in 52 of the 60 lymph nodes. In 142 autopsies, gross brain findings were reported. The most remarkable abnormality was hemorrhage ranging from petechial bleedings to punctate subarachnoid hemorrhages $(n=9)$, and to massive cerebral or cerebellar hemorrhage (87). SARS-COVID-2 viral particles were found in the frontal lobe of the brain and endothelial cells of the capillaries. Perivascular acute disseminated encephalomyelitis (ADEM)-like picture, and neocortical microscopic infarcts were also observed in autopsy findings (88). luga et al. (89) revealed adrenal gland findings who described small vessels with acute fibrinoid necrosis, subendothelial vacuolization, and apoptotic bodies. Furthermore, Yang et al. (90) studied the 12 post-mortem testicular biopsies, and observed Sertoli cell swelling and detachment from tubular basement membrane, reduced Leydig cells, mild lymphocytic inflammation, and intratubular cellular sloughing. They reported immunohistochemical positivity to markers such as CD3, CD20, CD68, CD138, and ACE-2 as well (91). In another study, the olfactory bulbs were edematous and oval, and microscopic examination showed diffuse edema, inflammatory cell infiltration, severe neuronal degeneration, and 
neuronal necrosis. Microglial nodules and scattered degenerative neurons were also observed in the ganglion cell regions (32).

\section{TREATMENT}

The most important symptomatic treatment for COVID-19 patients is oxygen therapy (92). The classes of drugs being evaluated or developed for the management of COVID-19 include antivirals, antibodies, anti-inflammatory agents, targeted immunomodulatory therapies, anticoagulants, and antifibrotics (28). The list of drugs for instance, in Tongji Hospital, Wuhan for the treatment of COVID-19 patients was as follows: Interferon-alpha (IFN-a), Lopinavir/ritonavir (LPV/r), Ribavirin, Chloroquine or hydroxychloroquine, Arbidol (93). Long et al. (93) showed that starting oxygen treatment less than 2 days following onset of hypoxic symptoms and the using of IFN-alpha among critically ill patients were both linked to a lower risk of COVID-19 mortality. Oral antivirals do not have the side effects of monoclonal antibodies, which must be administered in a hospital setting, and they are far less expensive (94). Remdesivir is a direct-acting antiviral drug that inhibits RNA-dependent RNA polymerase(RdRP) (95). It is an FDA-approved intravenous drug for use in adult and pediatric patients both older and less than 12 years of age for the treatment of COVID-19 requiring hospitalization (96). A 3-day regimen of remdesivir showed a tolerable safety profile among nonhospitalized patients at high risk for Covid-19 progression, and resulted in an 87 percent lower chance of hospitalization or mortality than placebo (97). The US Food and Drug Administration (FDA) issued an emergency use authorisation for Pfizer's COVID-19 antiviral, Paxlovid, on Dec 22, 2021. Paxlovid is a combination of two drugs: ritonavir plus the novel protease inhibitor PF-07321332. Paxlovid inhibits a protease that is needed for replication (98). On December 23, the FDA approved Merck Sharp \& Dohme's (MSD) molnupiravir, an oral antiviral. Molnupiravir causes the replicating virus to accumulate mistakes until it can no longer survive (99). Monoclonal antibodies (mAbs) have emerged as valuable tools for treating and detecting a variety of diseases due to their high specificity and reliability. The receptor-binding domain (RBD) of the SARS-CoV-2 spike protein has become a primary target for therapeutic Ab development since it is critical for viral infection (100). Bamlanivimab is a strong neutralizing mAb (IgG1 with an unmodified Fc region) to the $S$ protein that was generated from the convalescent plasma of a patient who had COVID-19 (100). The use of inhaled adenosine in COVID19 patients has resulted in a 6-day reduction in duration of stay. The modifying and regulating activities of adenosine on macrophages could explain its effectiveness (101). Purinergic receptors are important in understanding the COVID-19. P2X7 is one of the receptors recently discussed in COVID-19. It is ionotropic and has an affinity for ATP. P2X7R has been identified as a possible treatment target for COVID-19102 (102). Multiple drugs acting on different signaling pathways such as angiotensin-II receptor antagonists, blockers of RAS pathway, ACE inhibitors, inhibitors of serine protease such as TMPRSS2, and Tocilizumab, and Baricitinib inhibitors of the JAK/STAT pathway have been studied (103). Researchers are interested in the development of JAK inhibitors as a therapeutic intervention in COVID-19. The JAK/STAT pathway is involved in the release of cytokines and chemokines which regulate inflammation in organisms (104). The small molecular inhibitors are known to prevent the interaction of SP with ACE2 and other proteases. Arbidol, a membrane fusion inhibitor authorized for the influenza virus is currently being tested against COVID-19 in clinical trials (105). FDA has approved the emergency use of baricitinib (an oral JAK1/JAK2 inhibitor) (106), in combination with remdesivir, for the treatment of certain hospitalized patients with suspected or laboratory-confirmed COVID-19 (107). Compared with those who received standard treatment alone, 129 patients hospitalized for COVID-19, received tocilizumab (an IL-6 receptor-targeted antibody), in addition to standard treatment, were significantly less likely to need ventilation or die within 2 weeks (92). IL-6 is a major signal transducer and activator of transcription 3 (STAT3) stimulator, particularly during inflammation, and Hojyo et al. (108) hypothesize that IL-6-STAT3 signaling is a promising therapeutic target for the cytokine storm in COVID-19. Thromboembolic prophylaxis with subcutaneous low molecular weight heparin is recommended for all hospitalized patients with COVID-19 (28). Studies show that, the use of dexamethasone is associated with a lower risk of invasive mechanical ventilation and, for those already receiving invasive mechanical ventilation, a greater likelihood of early cessation (109). The hospitalized patients in New 
York with COVID-19 who were treated with hydroxychloroquine, azithromycin, or both, did not have significant differences in in-hospital mortality compared to those with neither treatment (110). To decrease the virus-ACE2 connection, researchers are using the CRISPR-Cas9 technique to generate point mutations in human ACE2 (111) (table I).

\begin{tabular}{|l|l|}
\hline Drug & Mechanism of action \\
Arbidol & $\begin{array}{l}\text { Targets S protein/ACE2 } \\
\text { interaction } \\
\text { Inhibits membrane fusion of } \\
\text { the viral envelope }\end{array}$ \\
\hline Camostat mesylate & $\begin{array}{l}\text { Inhibits TMPRSS2 } \\
\text { Prevent viral cell entry }\end{array}$ \\
\hline $\begin{array}{l}\text { Tocilizumab } \\
\text { Sarilumab }\end{array}$ & $\begin{array}{l}\text { Bind IL-6 receptor } \\
\text { Prevent IL-6 receptor } \\
\text { activation } \\
\text { Inhibit IL-6 signaling }\end{array}$ \\
\hline $\begin{array}{l}\text { Chloroquine } \\
\text { Hydroxychloroquine }\end{array}$ & $\begin{array}{l}\text { Inhibit viral entry and } \\
\text { endocytosis by multiple } \\
\text { mechanisms as well as host } \\
\text { immunomodulatory effects }\end{array}$ \\
$\begin{array}{l}\text { Lopinavir } \\
\text { Darunavir } \\
\text { Ribavirin } \\
\text { Remdesivir } \\
\text { Favipiravir }\end{array}$ & $\begin{array}{l}\text { protease } \\
\text { Inhibit viral RNA-dependent } \\
\text { RNA polymerase (RdRp) }\end{array}$ \\
\hline
\end{tabular}

Table I. SARS-CoV-2 Potential Drug Targets (112).

\section{COVID-19 VACCINES}

In the development of vaccines for viral diseases antigens are delivered to induce virus-specific neutralizing antibodies. Additional immunological responses may be needed for effective vaccine-induced immunity for many viruses, including CD4 and CD8 T cells with specific characteristics and positioning (113). Traditional immunization against viral infections is based on the use of the entire pathogen in a weakened or inactivated condition by chemical or physical alterations. To create immunological memory to a particular vaccine antigen, or even a toxin, inactivated vaccines which are replication-deficient or killed viruses or bacteria are administered (114). However, they typically give less protection for a shorter time and induce modest immunological responses, particularly cell-mediated immunity. As a consequence, inactivated vaccinations are given with a powerful adjuvant and require boosters to produce satisfactory and long-lasting immunity (115). Another method for vaccine development is to isolate viral proteins like the spike rather than the entire virus. The immune system reaction to the isolated protein is generally not as strong as it is to the full virus particle, but it is safer and easier to produce. Protein subunit vaccines have a low immunogenicity, and to produce a more robust immune response, an adjuvant must be included in the vaccine formulation (116). In SARS-CoV-2, the T cell response against the $S, M$, and $N$ subunit proteins was found to be the most prominent and long-lasting (117). Injecting patients with RNA or DNA encoding viral proteins is a more advanced method of vaccine development (118). DNA vaccines are extremely stable and require no refrigeration, making them ideal for use in endemic areas (119). mRNA vaccines are an attractive alternative to traditional vaccine technologies because of their high poten$c y$, ability to generate quickly, and potential for low-cost manufacturing and safe delivery. However, owing to the instability and inefficiency of mRNA distribution in vivo, their usage was limited until recently (120). Adenoviruses (Ad) are one of the most widely used vectors for vaccine production, with Ad5 being the most frequently employed non-replicating Ad vector (121). The S protein or RBD subunit of SARS-CoV-2 is expressed in most of the vaccines based on non-replicating Ad5 viral vectors $S$ (117). Because of its safety and lack of pre-existing immunity in humans, the chimp adenovirus (ChAdOx1) is a viable alternative to the human Ad vector (122). Virus-like particles (VLPS) have the same structure as viruses but lack the viral genome and are therefore non-infectious (123). $S$ protein spikes on the exterior of the produced SARS-CoV-2 VLPs make them excellent for vaccine development (124). Unlike subunit vaccines, VLPS are unable to connect directly to B cell receptors to produce (117). Low productivity and high costs limit the use of cell-based vaccinations. For example, a "synthetic mini-gene" producing the SARS-CoV-2 viral proteins $S, M, E, N$, and polyprotein protease $(P)$ was constructed using a lentiviral vector (LVSMENP) and transmitted to artificial APCS (APCS) (NCT04276896) (117). Currently, more than 200 COVID-19 vaccine candidates are being developed using a variety of technologies. The two front-runner vaccines based on mRNA platforms, Pfizer/ BioNTech BNT162b2 and Moderna mRNA-1273, have been approved by the US Food and Drug FDA for emergency use in mid-December 2020, with reported overall efficacy rates of 95 percent and 94.1 
percent, respectively (125).

\section{COVID19 AND ANIMALS}

Based on the biological features of bats and the high identity sequence between bat-nCoV and SARS-CoV-2, bats are considered as the natural reservoir of SARS-CoV-2 for now. The intermediate host is thought to be the pangolin. Snakes, minks, and turtles, as well as ferrets and domestic animals, should not be overlooked (126). Hamsters are susceptible to SARS-CoV infection with comparable viral replication in the upper and lower respiratory tract (127). Rosenke et al. (128) found that the SARS-CoV-2 RBD has a strong functional interaction with the hamster ACE2 receptor. The pathological features of SARS-CoV-2 infected hamsters' lungs are like those seen in COVID-19 patients. Syrian hamsters are an excellent small animal model for testing vaccinations, immunotherapies, and antiviral medications (129). Mathavarajah and Dellaire (130) used the recently reported crystal structure of ACE2 and the RBD of the SARS-CoV-2 spike protein to try to figure out why dogs are less susceptible to SARS-CoV-2 than cats. They discovered that a mutation at amino acid H34 found solely in dogs (H34Y) and not in feline ACE2 was the fundamental distinction between these domestic pets. As a result, H34 appears to be a crucial residue linked to the species' susceptibility to the SARS-CoV-2 virus. $\mathrm{H} 34 \mathrm{Y}$ is thought to reduce ACE2 and SARS-CoV-2 binding affinity. Strong ACE2 expression is found in tracheal and bronchial goblet cells, tracheobronchial submucosal gland serous epithelial cells, and type I and type II pneumocytes in cats. Cats can contract SARS-CoV-2 from their owners and are susceptible to experimental infection. They shed virus in the nasal turbinates, soft palates, tonsils, tracheas, lungs, and small intestines, with the live virus in all these tissues except the intestines and feces, implying minimal virus shedding via that route. There is currently no evidence of cat-to-human transmission (131). Other SARS-CoV-2 infections in pigs, dogs, chickens, and tree shrews have shown limited findings, with none demonstrating illness symptoms and only dogs shedding in feces but not tissue. Chickens have a high level of resistance to SARS-CoV, MERS-CoV, and SARS-CoV-2. In ferrets, the pattern of ACE2 expression resembles that in cats, except that it is absent in type I pneumocytes and tracheal and bronchial goblet cells
(132). The ferret is a great small animal model that can mimic many of the manifestations of human influenza virus infection (133). Ferrets are a COVID-19 infection and transmission animal model that could aid in the development of SARS-CoV-2 therapeutics and vaccines (134).

\section{COVID-19 AND CANCER}

The pathogenesis of COVID-19 and cancer share certain similarities, with both expressing inflammation, immunological dysregulation, and coagulopathy (135). Hematological cancer, lung cancer, and breast cancer patients have more vulnerability toward getting infected with Sars-CoV2 (136). Inflammation is linked to the development of cancer and promotes carcinogenesis (137). Angiotensin-converting enzyme 2 plays an important role in the development of cancer (138). The expression of ACE2 is higher in some cancers such as lung, cervical, pancreatic, and renal carcinomas, while the expression is decreased in breast, prostate, and liver cancers. Patients, particularly with prostate cancer, have higher expression of TMPRSS2 as compared to patients with renal, lung, colorectal, or pancreatic cancers, while other cancers have no significant expression of TMPRSS2 (139). COVID-19 cancer patients had much higher mortality and severe disease than the general population, according to data from the COVID-19 and Cancer Consortium (CCC19) cohort study, which comprised 1,018 patients (92). A year after the COVID-19 outbreak and the initial lockdown, it is apparent that the disease has taken a high toll on cancer patients, affecting every stage from screening to diagnosis, and treatment (140). Around 40000 fewer people than normal started cancer treatment in the UK last year, and US hospitals have been deluged by COVID-19 cases, rendering patients with cancer unable to obtain timely care. WHO has reported that one in three European countries had partially or completely interrupted cancer care services early in the pandemic (141). The COVID-19 diagnostic delay in the UK is expected to result in a $9.6 \%$ rise in breast cancer deaths, $16.6 \%$ increase in colon-rectal cancer deaths, 5.3 percent increase in lung cancer deaths, and 6.0 percent increase in esophageal cancer deaths during the following 5 years (142). A survey of 155 countries by WHO found that $42 \%$ of countries had disruption of services for cancer prevention and treatment; the degree of disruption 
was proportional to the extent of the pandemic in that country. The possible cause of this high risk to cancer patients with COVID-19 is surely the immunocompromised state of the patient (143). Coronavirus pneumonia brought about a $24 \%$ mortality in individuals with cancer while a 3\% mortality was observed with noncancer patients (144). Most cytotoxic agents used in chemotherapy cause bone marrow suppression which could ultimately result in thrombocytopenia and neutropenia, this further makes cancer patients more susceptible to infections (144). Radiation therapy has also been reported to damage lymphocytes resulting in lymphopenia (145). In Northern Italy, the study conducted on 25 patients with cancer and COVID-19 showed a high mortality rate of about $36 \%$ compared to $16.13 \%$ in non-cancerous COVID-19 patients, and lung cancer was prominent among cancer patients (146). A study in a New York hospital system and a multicenter study in China demonstrated that patients with lung cancer had a higher risk of adverse outcomes when compared with other cancer types (147). According to Dai et al. (148), lung cancer was the most common cancer histology in infected patients $(20.95 \%)$, followed by gastrointestinal cancer $(12.38 \%)$, breast cancer $(10.48 \%)$, thyroid cancer (10.48\%), and hematologic cancer (8.57\%) of 105 patients. The incidence of mortality in lung cancer patients infected with SARS-CoV-2 was reported to be up by four times (146). Although patients receiving chemotherapy appeared to be at a higher risk of severe illness from COVID-19, delaying chemotherapy is not advised, whereas individuals receiving only radiotherapy showed no significant differences in severe events when compared to individuals without cancer (92). The likelihood of radiotherapy being preferred by clinicians to other forms of cancer treatment is supported by the fact that in the UK, radiotherapy services decreased by only $10 \%$ during the 10-week lockdown from March to May 2020, compared with a $40 \%$ reduction in surgery (143). Data from both Italy and Latin America suggest that delivery of radiotherapy services was less affected than other modalities (143). Depending on the stage of illness, the progression of cancer can be a challenge for delaying procedures in cancer patients. Delays in the case of prostate, breast, cervical, or skin cancer in early stages can be tolerated but pancreatic, lung and hematological cancers such as leukemia require treatment as soon as possible (146). To avoid more suffering to patients from the deadly pair of COVID-19 and can- cer, oncologists along with cancer societies, advise putting cytotoxic chemotherapy on hold and waiting until the SARS-CoV-2 virus becomes negative in the body (149). Cancer treatment regimens that do not affect outcomes of COVID-19 in cancer patients may not need to be altered (150). The presence of COVID-19 with malignancy makes diagnosis extremely challenging. Diagnosis of radiographs can be similar in both COVID-19 and cancer which may deceive the healthcare professional in making an accurate diagnosis (146). Carbohydrate antigens (CA) 125 and 153, carcinoembryonic antigens (CEA), human epididymis protein 4 (HE4), CRP, and cytokeratin-19 fragment (CYFRA21-1) are common markers in both COVID-19 and cancer; these markers are raised in both COVID-19 and cancer (146). Cancer patients are at a higher risk of both arterial and venous thromboembolism, especially if they are undergoing systemic chemotherapy (151). Cancer affects one's immune system and physiology through higher D-Dimer, lower levels of albumin, longer prothrombin time, and higher neutrophil counts (152). Sallah et al. (153) evaluated the occurrence of DIC in 1117 patients with solid tumors. Of these patients, 76 (6.8\%) were diagnosed with DIC. Thrombocytopenia, hypofibrinogenemia, elevated D-dimer and, fibrinogen degradation products were the most common coagulation abnormalities encountered in patients with DIC. Tumoral factors such as tissue factor (TF), podoplanin, plasminogen activator factor (PAl-1), cytokines, $\mathrm{NET}$, and mucins trigger the risk for thrombosis (146). The type of cancer changes with the severity of coagulation, e.g., adenocarcinomas, lung cancer, pancreatic cancer, gastrointestinal cancer, and ovarian cancer have elevated risk for coagulation, while the risk is lower in breast and renal carcinoma compared to no risk associated with prostate cancer and melanoma (146). Cancer and COVID19 treatments generally have similar goals, and several anti-cancer medications are being examined in clinical trials to see whether they might be repurposed for COVID-19 (154). Recombinant IFNy and IFNa2b have been widely utilized to treat cancer, and IFN administration has emerged as a promising treatment for COVID-19 (155). Cancer immunotherapy includes pharmaceuticals such as immune checkpoint inhibitors and monoclonal antibodies (MAbs), immunogene therapy, cell therapy, and vaccines (156). The same treatment regimen that is utilized to prevent or lessen cytokine storm in cancer patients receiving CAR-T cell therapy could be 
used to lower the risk of cytokine storm in COVID-19 patients. As a result, antibodies that target the IL- 6 receptor (tocilizumab and sarilumab), IL-6 (siltuximab), and other receptor antagonists (a1-adrenergic receptor antagonist, prazosin) for preventing cytokine storm are useful therapeutic options for the treatment of cancer patients with COVID-19 (157). PD1 inhibitors are immune checkpoint inhibitors $(\mathrm{ICl})$, which have gained potential importance in solid cancer treatment (158). Reduction in sepsis or infection after pneumonia and inflammatory response syndrome was observed in COVID-19 patients administered with PD-1 inhibitors (146). ICls would likely to be a protective factor against the onset of COVID-19 infection (159). Ruxolitinib a Janus-associated kinase (JAK) inhibitor has been reported to reduce cytokine-mediated inflammation, reducing severe events such as ARDS in COVID-19 infected patients, and many trials are currently active (146).

\section{CONCLUSIONS}

The results of COVID-19 imply that heavy polluters must act quickly and strongly on climate change to prevent a far more hazardous future and a more difficult recovery course (160). The COVID-19 dilemma teaches us a lot about what to expect in the forthcoming global climate crisis. Global emergencies are not new, but our ability to understand, avoid, and respond them has never been better (161). The only safe method to deal with COVID is to develop a vaccination, and the only way to combat climate change is to convert to a low-carbon system (162). Medications now being evaluated for COVID-19 repositioning can be divided into two categories: 1) medications that may impede one or more steps of the coronavirus lifecycle, and 2) drugs that may counteract the consequences of SARS-CoV-2 infection, such as the heightened immune response and massive cytokine release (163). More effective vaccines will need to be developed specifically for immunocompromised individuals. Several anti-cancer medications, in addition to antiviral and anti-inflammatory medications, could be repurposed to treat COVID-19 (154). SARS-CoV-2 can infect a wide range of animals. Several animal models, including the mouse, hamster, cat, ferret, and monkey, have been identified as suitable for evaluating the efficacy and safety of antiviral medicines or testing experimental vaccinations against SARS-CoV-2 (164).

\section{ETHICS}

\section{Fundings}

There were no institutional or private fundings for this article.

\section{Conflict of interests}

The authors have declared no conflict of interests.

\section{Availability of data and materials}

The data underlying this article are available in the article.

\section{Authors' contribution}

Conceptualization: AAN, FC, Dd, LC, FN and LA; writing-original preparation: AAN, FC, Dd, LC and FN; writing-reviewing and editing: AAN, FC, Dd, LC, FN and LA; supervision: FC and LA.

\section{Ethical approval}

N/A. 


\section{REFERENCES}

1. Velavan TP, Meyer CG. The COVID-19 epidemic. Trop Med Int Heal 2020;25(3):278-80. Doi:10.1111/tmi.13383.

2. Ouassou $H$, Kharchoufa $L$, Bouhrim $M$, et al. Evaluation and Prevention 2020;1-7. Doi: 10.1155/2020/1357983.

3. Schlottau K, Rissmann M, Graaf A, et al. SARSCoV-2 in fruit bats, ferrets, pigs, and chickens: an experimental transmission study. The Lancet Microbe 2020;1(5):e218-e225. Doi:10.1016/ s2666-5247(20)30089-6.

4. Latinne A, Hu B, Olival KJ, et al. Origin and cross-species transmission of bat coronaviruses in China. Nat Commun 2020;11(1):1-15. Doi:10.1038/s41467-020-17687-3.

5. Burki T. The origin of SARS-CoV-2. Lancet Infect Dis 2020;20(9):1018-9. Doi:10.1016/S14733099(20)30641-1.

6. Mariano G, Farthing RJ, Lale-Farjat SLM, Bergeron JRC. Structural Characterization of SARS-CoV-2: Where We Are, and Where We Need to Be. Front Mol Biosci 2020;7:1-28. Doi:10.3389/fmolb.2020.605236.

7. Kumar M, Al Khodor S. Pathophysiology and treatment strategies for COVID-19. J Transl Med 2020;18(1):1-9. Doi:10.1186/s12967-020-02520-8.

8. Steinbrecht $W$, Kubistin D, Plass-Dülmer C, et al. COVID-19 Crisis Reduces Free Tropospheric Ozone Across the Northern Hemisphere. Geophys Res Lett 2021;48(5):1-11. Doi:10.1029/2020GL091987.

9. Hou Y, Zhao J, Martin W, et al. New insights into genetic susceptibility of COVID-19: an ACE2 and TMPRSS2 polymorphism analysis. 2020;18(216):1-8.

10. Viveiros A, Rasmuson J, Vu J, et al. Sex differences in COVID-19: Candidate pathways, genetics of ACE2, and sex hormones. Am J Physiol - Hear Circ Physiol 2021;320(1):H296-H304. Doi:10.1152/AJPHEART.00755.2020.

11. Singh A K, Sing, A, Dubey A K. Repurposed Therapeutic Strategies towards COVID-19 Potential Targets Based on Genomics and Protein Structure Remodeling', in M. Agrawal, S. Biswas (eds.), Biotechnology to Combat COVID-19 [Working Title], IntechOpen, London 2021z. Doi: 10.5772/intechopen.96728.

12. Gibb R, Redding DW, Chin KQ, et al. Zoonotic host diversity increases in human-dominated ecosystems. Nature 2020;584(7821):398-402. Doi:10.1038/s41586-020-2562-8.

13. Buck JC, Weinstein SB. The ecological consequences of a pandemic: The ecological effects of COVID-19. Biol Lett 2020;16(11):1-6. Doi:10.1098/rsbl.2020.0641 rsbl20200641.

14. Faust CL, McCallum HI, Bloomfield LSP, Gottdenker NL, Gillespie TR, Torney CJ, et al. Pathogen spillover during land conversion. Faust, Ecology Letters. Wiley Online Library. Published online 2018:471-83.

15. Dobson AP, Pimm SL, Hannah L, et al. Ecology and economics for pandemic prevention. Science 2020;369(6502):379-381. Doi:10.1126/ science.abc3189.

16. Ali N, Islam F. The Effects of Air Pollution on COVID-19 Infection and Mortality - A Review on Recent Evidence. Front Public Heal 2020;8(2):17. Doi:10.3389/fpubh.2020.580057.

17. Copat C, Cristaldi A, Fiore $M$, et al. The role of air pollution (PM and NO2) in COVID-19 spread and lethality: A systematic review. Environ Res 2020;191:1-10. Doi:10.1016/j.envres.2020.110129.

18. Gougis P, Fenioux C, Funck-Brentano C, et al. Anticancer drugs and COVID-19 antiviral treatments in patients with cancer: What can we safely use? Eur J Cancer 2020;136:1-3. Doi:10.1016/j.ejca.2020.05.027.

19. Khan I, Shah D, Shah SS. COVID-19 pandemic and its positive impacts on environment: an updated review. Int J Environ Sci Technol 2021;18(2):52130. Doi:10.1007/s13762-020-03021-3.

20. Yang J, Petitjean SJL, Koehler M, et al. Molecular interaction and inhibition of SARS-CoV-2 binding to the ACE2 receptor. Nat Commun 2020;11(1):110. Doi:10.1038/s41467-020-18319-6.

21. Thunders M, Delahunt B. Gene of the month: TMPRSS2 (transmembrane serine protease 2). J Clin Pathol 2020;73(12):773-776. Doi:10.1136/ jclinpath-2020-206987.

22. Matsuyama T, Kubli SP, Yoshinaga SK, Pfeffer K, Mak TW. An aberrant STAT pathway is central to COVID-19. Cell Death Differ 2020;27(12):320925. Doi:10.1038/s41418-020-00633-7.

23. Farooqui AA. Contribution of gut microbiota and multiple organ failure in the pathogenesis of COVID-19 infection. Published online 2021:255-66. 
24. Attaway AH, Scheraga RG, Bhimraj A, Biehl M, Hatipoğ Lu U. Severe covid-19 pneumonia: Pathogenesis and clinical management. BMJ 2021;372:1-19. Doi:10.1136/bmj.n436.

25. Grasselli G, Tonetti T, Protti A, et al. Pathophysiology of COVID-19-associated acute respiratory distress syndrome: a multicentre prospective observational study. Lancet Respir Med 2020;8(12):1201-8. Doi:10.1016/S22132600(20)30370-2.

26. McCoy K, Peterson A, Tian Y, Sang Y. Immunogenetic association underlying severe covid-19. Vaccines 2020;8(4):1-13. Doi:10.3390/ vaccines 8040700 .

27. MaC,CongY,ZhangH.COVID-19andtheDigestive System. Am J Gastroenterol 2020;115(7):1003-6. Doi:10.14309/ajg.0000000000000691.

28. Wiersinga WJ, Rhodes A, Cheng AC, Peacock SJ, Prescott HC. Pathophysiology, Transmission, Diagnosis, and Treatment of Coronavirus Disease 2019 (COVID-19): A Review. JAMA - J Am Med Assoc 2020;324(8):782-93. Doi:10.1001/ jama.2020.12839.

29. Zhou L, Xu Z, Castiglione GM, Soiberman US, Eberhart CG, Duh EJ. ACE2 and TMPRSS2 are expressed on the human ocular surface, suggesting susceptibility to SARS-CoV-2 infection. Ocul Surf 2020;18(4):537-44. Doi:10.1016/j.jtos.2020.06.007.

30. He X, Lau EHY, Wu P, et al. Temporal dynamics in viral shedding and transmissibility of COVID-19. Nat Med 2020;26(5):672-75. Doi:10.1038/s41591-020-0869-5.

31. Lauer SA, Grantz KH, Bi Q, et al. The incubation period of coronavirus disease 2019 (CoVID-19) from publicly reported confirmed cases: Estimation and application. Ann Intern Med 2020;172(9):577-82. Doi:10.7326/M20-0504.

32. Stoyanov GS, Petkova L, Dzhenkov DL, Sapundzhiev NR, Todorov I. Gross and Histopathology of COVID-19 With First Histology Report of Olfactory Bulb Changes. Cureus 2020;12(12):17. Doi:10.7759/cureus.11912.

33. Richardson S, Hirsch JS, Narasimhan M, et al. Presenting Characteristics, Comorbidities, and Outcomes among 5700 Patients Hospitalized with COVID-19 in the New York City Area. JAMA - J Am Med Assoc 2020;323(20):2052-2059. Doi:10.1001/jama.2020.6775.

34. Lauring AS, Hodcroft EB. Genetic Variants of SARS-CoV-2 - What Do They Mean? JAMA - J Am Med Assoc 2021;325(6):529-531. Doi:10.1001/ jama.2020.27124.
35. Korber B, Fischer WM, Gnanakaran S, et al. Tracking Changes in SARS-CoV-2 Spike: Evidence that D614G Increases Infectivity of the COVID-19 Virus. Cell 2020;182(4):812-27.e19. Doi:10.1016/j.cell.2020.06.043.

36. Li Q, Wu J, Nie J, et al. The Impact of Mutations in SARS-CoV-2 Spike on Viral Infectivity and Antigenicity. Cell 2020;182(5):1284-94.e9. Doi:10.1016/j.cell.2020.07.012.

37. Larsen CS, Paludan SR. Corona's new coat: SARS-CoV-2 in Danish minks and implications for travel medicine. Travel Med Infect Dis 2020;38:1-2. Doi:10.1016/j. tmaid.2020.101922.

38. Kidd M, Richter A, Best A, et al. S-Variant SARSCoV-2 Lineage B1.1.7 Is Associated With Significantly Higher Viral Load in Samples Tested by TaqPath Polymerase Chain Reaction. J Infect Dis 2021;223(10):1666-70. Doi:10.1093/infdis/ jiab082.

39. Wise J. Covid-19: The E484K mutation and the risks it poses. BMJ 2021;372(February):1-2. Doi:10.1136/bmj.n359.

40. Chauhan I, Shutterstock AP. Coronavirus variants are spreading in India - What. Nature 2021;593:321-2.

41. Bruel T, Simon-lorière E, Rey FA, Schwartz O. Reduced sensitivity of SARS-CoV-2 variant Delta to antibody neutralization. Nature 2021:122. Doi:10.1038/s41586-021-03777-9.

42. Wink PL, Volpato FCZ, Monteiro FL, et al. First identification of SARS-CoV-2 Lambda (C.37) variant in Southern Brazil. medRxiv 2021:1-11.

43. Araf $Y$, Akter $F$, Tang $Y$, et al. Omicron variant of SARS-CoV-2: Genomics, transmissibility, and responses to current COVID-19 vaccines. J Med Virol 2022;(December 2021):1-8. Doi:10.1002/ jmv.27588.

44. Huang J, Cheng A, Kumar R, et al. Hypoalbuminemia predicts the outcome of COVID-19 independent of age and co-morbidity. J Med Virol 2020;92(10):2152-8. Doi:10.1002/jmv.26003.

45. Khourssaji M, Chapelle V, Evenepoel A, et al. A biological profile for diagnosis and outcome of COVID-19 patients. Clin Chem Lab Med 2020;58(12):2141-50. Doi:10.1515/cclm-20200626.

46. Yao Y, Cao J, Wang Q, et al. D-dimer as a biomarker for disease severity and mortality in COVID-19 patients: A case control study. J Intensive Care 2020;8(1):1-11. Doi:10.1186/ s40560-020-00466-z. 
47. Al-Samkari H, Karp Leaf RS, Dzik WH, et al. COVID-19 and coagulation: Bleeding and thrombotic manifestations of SARS-CoV-2 infection. Blood 2020;136(4):489-500. Doi:10.1182/ BLOOD.2020006520.

48. Iba $\mathrm{T}$, Levy JH, Connors JM, Warkentin $\mathrm{TE}_{\text {, }}$ Thachil J, Levi M. The unique characteristics of COVID-19 coagulopathy. Crit Care 2020;24(1):411. Doi:10.1186/s13054-020-03077-0.

49. Hadid T, Kafri Z, Al-Katib A. Coagulation and anticoagulation in COVID-19. Blood Rev 2021;47:1-11. Doi:10.1016/j.blre.2020.100761.

50. Magán-Fernández A, Rasheed Al-Bakri SM, O'Valle F, Benavides-Reyes C, Abadía-Molina F, Mesa F. Neutrophil Extracellular Traps in Periodontitis. Cells 2020;9(6):1-11. Doi:10.3390/ cells9061494.

51. Ragab D, Salah Eldin H, Taeimah M, Khattab R, Salem R. The COVID-19 Cytokine Storm; What We Know So Far. Front Immunol 2020;11:1-4. Doi:10.3389/fimmu.2020.01446.

52. Guo H, Sheng Y, Li W, et al. Coagulopathy as a Prodrome of Cytokine Storm in COVID-19-Infected Patients. Front Med 2020;71-7. Doi:10.3389/fmed.2020.572989.

53. Ahmadian E, Hosseiniyan Khatibi SM, Razi Soofiyani S, et al. Covid-19 and kidney injury: Pathophysiology and molecular mechanisms. Rev Med Virol 2021;31(3):1-13. Doi:10.1002/ rmv.2176.

54. Bohn MK, Hall A, Sepiashvili L, Jung B, Steele S, Adeli K. Pathophysiology of COVID-19: Mechanisms underlying disease severity and progression. Physiology 2020;35(5):288-301. Doi:10.1152/physiol.00019.2020.

55. Wang F, Wang H, Fan J, Zhang Y, Wang H, Zhao Q. Pancreatic Injury Patterns in Patients With Coronavirus Disease 19 Pneumonia. Gastroenterology 2020;159(1):367-70. Doi:10.1053/j. gastro.2020.03.055.

56. Cuschieri S, Grech S. COVID-19 and diabetes: The why, the what and the how. J Diabetes Complications 2020;34(9):1-5. Doi:10.1016/j. jdiacomp.2020.107637.

57. KopelJ, Goyal H, Perisetti A. Antibody tests for COVID-19. Baylor Univ Med Cent Proc 2021;34(1):6372. Doi:10.1080/08998280.2020.1829261.

58. Machado BAS, Hodel KVS, Barbosa-Júnior VG, Soares MBP, Badaró R. The main molecular and serological methods for diagnosing covid-19: An overview based on the literature. Viruses 2021;13(1):1-36. Doi:10.3390/v13010040.
59. Islam KU, Iqbal J. An Update on Molecular Diagnostics for COVID-19. Front Cell Infect Microbiol 2020;10:1-11. Doi:10.3389/ fcimb.2020.560616.

60. Lim J, Lee J. Current laboratory diagnosis of coronavirus disease 2019. Korean J Intern Med 2020;35(4):741-8. Doi:10.3904/KJIM.2020.257.

61. Cevik M, Tate M, Lloyd O, Maraolo AE, Schafers J, Ho A. SARS-CoV-2, SARS-CoV, and MERS-CoV viral load dynamics, duration of viral shedding, and infectiousness: a systematic review and meta-analysis. The Lancet Microbe 2021;2(1):e13-e22. Doi:10.1016/s2666-5247(20)30172-5.

62. Wang $\mathrm{D}, \mathrm{Hu} \mathrm{B}, \mathrm{Hu} \mathrm{C}$, et al. Clinical Characteristics of 138 Hospitalized Patients with 2019 Novel Coronavirus-Infected Pneumonia in Wuhan, China. JAMA - J Am Med Assoc 2020;323(11):1061-1069. Doi:10.1001/ jama.2020.1585.

63. Kilic T, Weissleder R, Lee $H$. Molecular and Immunological Diagnostic Tests of COVID-19: Current Status and Challenges. iScience 2020;23(8):1-19. Doi:10.1016/j. isci.2020.101406.

64. Tan C, Fan D, Wang $N$, et al. Applications of digital PCR in COVID-19 pandemic. View. 2021;2(2):1-7. Doi:10.1002/viw.20200082.

65. Notomi T, Okayama H, Masubuchi $H$, et al. Loop-mediated isothermal amplification of DNA. Nucleic Acids Res 2000;28(12):1-7. Doi:10.1093/nar/28.12.e63.

66. Rabe BA, Cepko C. SARS-CoV-2 detection using isothermal amplification and a rapid, inexpensive protocol for sample inactivation and purification. Proc Natl Acad Sci U S A. 2020;117(39):2445024458. Doi:10.1073/pnas.2011221117.

67. Lau YL, Ismail I binti, Mustapa NI binti, et al. Development of a reverse transcription recombinase polymerase amplification assay for rapid and direct visual detection of Severe Acute Respiratory Syndrome Coronavirus 2 (SARSCoV-2). PLoS One. 2021;16:2-9. Doi:10.1371/ journal.pone.0245164.

68. Anzalone A V., Koblan LW, Liu DR. Genome editing with CRISPR-Cas nucleases, base editors, transposases and prime editors. Nat Biotechnol 2020;38(7):824-44. Doi:10.1038/s41587020-0561-9.

69. Broughton JP, Deng $X, Y u G$, et al. CRISPRCas12-based detection of SARS-CoV-2. Nat Biotechnol 2020;38(7):870-4. Doi:10.1038/ s41587-020-0513-4. 
70. Su S, Shen J, Zhu L, et al. Involvement of digestive system in COVID-19: manifestations, pathology, management and challenges. Therap Adv Gastroenterol 2020;13:1-12. Doi:10.1177/1756284820934626.

71. Mohanty SK, Satapathy A, Naidu MM, et al. Severe acute respiratory syndrome disease 19 ( COVID-19 ) - anatomic pathology perspective on current knowledge. Diagn Pathol 2020;15(1):1-17.

72. Elsoukkary SS, Mostyka M, Dillard A, et al. Autopsy Findings in 32 Patients with COVID-19: A Single-Institution Experience. Pathobiology 2021;88(1):56-68. Doi:10.1159/000511325.

73. Menter T, Haslbauer JD, Nienhold R, et al. Postmortem examination of COVID-19 patients reveals diffuse alveolar damage with severe capillary congestion and variegated findings in lungs and other organs suggesting vascular dysfunction. Histopathology 2020;77(2):198209. Doi:10.1111/his.14134.

74. Schaller T, Hirschbühl K, Burkhardt $K$, et al. Postmortem Examination of $\mathrm{Pa}$ tients with COVID-19. JAMA - J Am Med Assoc 2020;323(24):2518-20. Doi:10.1001/ jama.2020.8907.

75. Xiao F, Tang M, Zheng X, Liu Y, Li X, Shan H. Evidence for Gastrointestinal Infection of SARSCoV-2. Gastroenterology 2020;158(6):1831-3. e3. Doi:10.1053/j.gastro.2020.02.055.

76. Lagana SM, Kudose S, luga AC, et al. Hepatic pathology in patients dying of COVID-19: a series of 40 cases including clinical, histologic, and virologic data. Mod Pathol. 2020;33(11):214755. Doi:10.1038/s41379-020-00649-x.

77. Santoriello D, Khairallah P,BombackAS, etal. Postmortem Kidney Pathology Findings in Patients with COVID-19.J Am Soc Nephrol 2020;31(9):215867. Doi:10.1681/ASN.2020050744.

78. Giavedoni P, Podlipnik Pericàs, Juan M. S, Fuertes de Vega I, et al. Skin Manifestations in COVID-19: Prevalence and Relationship with Disease Severity. J Clin Med 2020;9(10):1-12.

79. Kaya G, Kaya A, Saurat J-H. Clinical and Histopathological Features and Potential Pathological Mechanisms of Skin Lesions in COVID-19: Review of the Literature. Dermatopathology 2020;7(1):3-16. Doi:10.3390/dermatopathology7010002.

80. Fox SE, Li G, Akmatbekov A, et al. Unexpected features of cardiac pathology in COVID-19 infection. Circulation 2020:1123-5. Doi:10.1161/ CIRCULATIONAHA.120.049465.
81. Letícia S, Toledo DO, Nogueira LS, Carvalho G. COVID-19: Review and hematologic impact. Clin Chim Acta 2020;510:170-6.

82. Duarte FB, Lemes RPG, Duarte IA, Duarte BA, Duarte JVA. Hematological changes in Covid-19 infections. Rev Assoc Med Bras 2020;66(2):99. Doi:10.1590/1806-9282.66.2.99.

83. Harris CK, Hung YP, Nielsen GP, Stone JR, Ferry JA. Bone Marrow and Peripheral Blood Findings in Patients Infected by SARS-CoV-2. Am J Clin Pathol 2021;155(5):627-37. Doi:10.1093/ ajcp/aqaa274.

84. XuX, ChangXN,PanHX, etal.[Pathologicalchanges of the spleen in ten patients with coronavirus disease 2019(COVID-19) by postmortem needle autopsy]. Zhonghua bing li xue za zhi $=$ Chinese J Pathol 2020;49(6):576-82. Doi:10.3760/ cma.j.cn112151-20200401-00278.

85. Liu Q, Shi Y, Cai J, et al. Pathological changes in the lungs and lymphatic organs of 12 COVID-19 autopsy cases. Natl Sci Rev 2020;7(12):186878. Doi:10.1093/nsr/nwaa247.

86. Bryce C, Grimes Z, Pujadas E, et al. Pathophysiology of SARS-CoV-2: the Mount Sinai COVID-19 autopsy experience. Mod Pathol 2021;34:145667. Doi:10.1038/s41379-021-00793-y.

87. Mukerji SS, Solomon IH. What can we learn from brain autopsies in COVID-19? Neurosci Lett 2021;742:1-7. Doi:10.1016/j.neulet.2020.135528.

88. Tabary M, Khanmohammadi S, Araghi F, Dadkhahfar S, Tavangar SM. Pathologic features of COVID-19: A concise review. Pathol Res Pract 2020;216(9):1-5. Doi:10.1016/j.prp.2020.153097.

89. Iuga AC, Marboe CC, Yilmaz MM, Lefkowitch JH, Gauran C, Lagana SM. Adrenal vascular changes in COVID-19 autopsies. Arch Pathol Lab Med 2020;144(10):1159-60. Doi:10.5858/ arpa.2020-0248-LE.

90. Yang $M$, Chen S, Huang B, etal. Pathological Findings in the Testes of COVID-19 Patients: Clinical Implications. Eur Urol Focus 2020;6(5):1124-9. Doi:10.1016/j.euf.2020.05.009.

91. Mondello C, Roccuzzo S, Malfa O, et al. Pathological Findings in COVID-19 as a Tool to Define SARS-CoV-2 Pathogenesis. A Systematic Review. Front Pharmacol 2021;12:1-22. Doi:10.3389/fphar.2021.614586.

92. Liu C, Zhao Y, Okwan-Duodu D, Basho R, Cui X. COVID-19 in cancer patients: risk, clinical features, and management. Cancer Biol Med 2020;17(3):519-27. Doi:10.20892/j.issn.20953941.2020.0289. 
93. Long L, Wu L, Chen L, et al. Effect of early oxygen therapy and antiviral treatment on disease progression in patients with COVID-19: A retrospective study of medical charts in China. PLoS Negl Trop Dis 2021;15(1):1-15. Doi:10.1371/journal.pntd.0009051.

94. Burki TK. The role of antiviral treatment in the COVID-19 pandemic. Lancet Respir Med 2022;10(2):e18. Doi:10.1016/s22132600(22)00011-x.

95. Gordon CJ, TchesnokovEP, Woolner E, et al. Remdesivir is a direct-acting antiviral that inhibits RNA-dependent RNA polymerase from severe acute respiratory syndrome coronavirus 2 with high potency. J Biol Chem 2020;295(20):678597. Doi:10.1074/jbc.RA120.013679.

96. Saito S, Hayakawa K, Mikami A, et al. Investigator initiated clinical trial of remdesivir for the treatment of COVID-19 in Japan. Glob Heal Med 2021;3(2):62-66. Doi:10.35772/ ghm.2020.01106.

97. Gottlieb RL, Vaca CE, Paredes R, et al. Early Remdesivir to Prevent Progression to Severe Covid-19 in Outpatients. N Engl J Med 2022;386(4):305-15. Doi:10.1056/nejmoa2116846.

98. Pfizer. Pfizer Announces Additional Phase 2/3 Study Results Confirming Robust Efficacy of Novel COVID-19 Oral Antiviral Treatment Candidate in Reducing Risk of Hospitalization or Death. 2021. Available from: https://WwwPfizerCom/ News/Press-Release/Press-Release-Detail/Pfizer-Announces-Additional-Phase-23-Study-Results. Last accessed: Feb 23, 2022.

99. Jayk Bernal A, Gomes da Silva MM, Musungaie DB, et al. Molnupiravir for Oral Treatment of Covid-19 in Nonhospitalized Patients. N Engl J Med 2022;386(6):509-20. Doi:10.1056/nejmoa2116044.

100. Hwang YC, Lu RM, Su SC, et al. Monoclonal antibodies for COVID-19 therapy and SARSCoV-2 detection. J Biomed Sci 2022;29(1):1-50. Doi:10.1186/s12929-021-00784-w.

101. Caracciolo M, Correale P, Mangano C, et al. Efficacy and Effect of Inhaled Adenosine Treatment in Hospitalized COVID-19 Patients. Front Immunol 2021;12:1-12. Doi:10.3389/fimmu.2021.613070.

102. Franciosi MLM, Lima MDM, Schetinger MRC, Cardoso AM. Possible role of purinergic signaling in COVID-19. Mol Cell Biochem 2021;476(8):2891-8. Doi:10.1007/s11010-021-04130-4.
103. Battagello DS, Dragunas G, Klein MO, Ayub ALP, Velloso FJ, Correa RG. Unpuzzling COVID-19: Tissue-related signaling pathways associated with SARS-CoV-2 infection and transmission. Clin Sci 2020;134(16):2137-60. Doi:10.1042/CS20200904.

104. Satarker S, Tom AA, Shaji RA, Alosious A, Luvis M, Nampoothiri M. JAK-STAT Pathway Inhibition and their Implications in COVID-19 Therapy. Postgrad Med 2021;133(5):489-507. Doi:10 .1080/00325481.2020.1855921.

105. Choudhary S, Silakari O. Scaffold morphing of arbidol (umifenovir) in search of multi-targeting therapy halting the interaction of SARS-CoV-2 with ACE2 and other proteases involved in COVID-19. Virus Res 2020;289:1-20. Doi:10.1016/j.virusres.2020.198146.

106. Moura RA, Fonseca JE. JAK Inhibitors and Modulation of B Cell Immune Responses in Rheumatoid Arthritis. Front Med 2021;7:1-18. Doi:10.3389/fmed.2020.607725.

107. FDA. Coronavirus (COVID-19) Update: FDA Authorizes Drug Combination for Treatment of COVID-19. Food Drug Adm 2020:19-22. Available from: https://www.fda.gov/news-events/ press-announcements/coronavirus-covid-19-update-fda-authorizes-drug-combination-treatment-covid-19\#: :text=Today\%2C the U.S. Food and,or older requiring supplemental oxygen\%2C. Last accessed: Feb 23, 2022.

108. Hojyo S, Uchida M, Tanaka K, et al. How COVID-19 induces cytokine storm with high mortality. Inflamm Regen 2020;40(1):1-7. Doi:10.1186/s41232-020-00146-3.

109. Group TRC. Dexamethasone in Hospitalized Patients with Covid-19. N EnglJ Med 2021;384(8):693704. Doi:10.1056/nejmoa2021436.

110. Rosenberg ES, Dufort EM, Udo T, et al. Association of Treatment with Hydroxychloroquine or Azithromycin with In-Hospital Mortality in Patients with COVID-19 in New York State. JAMA - J Am Med Assoc. 2020;323(24):2493502. Doi:10.1001/jama.2020.8630.

111. Tanaka P, Santos J, Oliveira E, et al. A Crispr-Cas9 System Designed to Introduce Point Mutations into the Human ACE2 Gene to Weaken the Interaction of the ACE2 Receptor with the SARS-CoV-2 S Protein. Preprints 2020;0-2. Doi:10.20944/PREPRINTS202005.0134.V1.

112. Sanders JM, Monogue ML, Jodlowski TZ, Cutrell JB. Pharmacologic Treatments for Coronavirus Disease 2019 (COVID-19): A Review. 
JAMA - J Am Med Assoc 2020;323(18):1824-36. Doi:10.1001/jama.2020.6019.

113. Graham BS, Gilman MSA, McLellan JS. Structure-based vaccine antigen design. Annu Rev Med 2019;70:91-104. Doi:10.1146/annurev-med-121217-094234.

114. Vrba SM, Kirk NM, Brisse ME, Liang Y, Ly H. Development and applications of viral vectored vaccines to combat zoonotic and emerging public health threats. Vaccines 2020;8(4):1-31. Doi:10.3390/vaccines 8040680 .

115. Lee N-H, Lee J-A, Park S-Y, Song C-S, Choi I-S, Lee J-B. A review of vaccine development and research for industry animals in Korea. Clin Exp Vaccine Res 2012;1(1):18-34. Doi:10.7774/cevr.2012.1.1.18.

116. Azmi F, Fuaad AAHA, Skwarczynski M, Toth I. Recent progress in adjuvant discovery for peptide-based subunit vaccines. Hum Vaccines Immunother 2014;10(3):778-96. Doi:10.4161/hv.27332.

117. Chung JY, Thone MN, Kwon YJ. COVID-19 vaccines: The status and perspectives in delivery points of view. Adv Drug Deliv Rev 2021;170:1 25. Doi:10.1016/j.addr.2020.12.011.

118. Jonathan K, Eric S. Coronavirus Structure, Vaccine and Therapy Development. Biophys Soc 2020. Available from: https://www.biophysics.org/ blog/coronavirus-structure-vaccine-and-therapy-development. Last accessed: 23 Feb, 2022.

119. Ingolotti M, Kawalekar O, Shedlock DJ, Muthumani K, Weiner DB. DNA vaccines for targeting bacterial infections. Expert Rev Vaccines 2010;9(7):747-63. Doi:10.1586/erv.10.57.

120. Pardi N, Hogan MJ, Porter FW, Weissman D. mRNA vaccines-a new era in vaccinology. Nat Rev Drug Discov 2018;17(4):261-79. Doi:10.1038/nrd.2017.243.

121. Robert-Guroff M. Replicating and non-replicating viral vectors for vaccine development. Curr Opin Biotechnol 2007;18(6):546-56. Doi:10.1016/j.copbio.2007.10.010.

122. Humphreys IR, Sebastian S. Novel viral vectors in infectious diseases. Immunology 2018;153(1):1-9. Doi:10.1111/imm.12829.

123. Roldão A, Silva AC, Mellado MCM, Alves PM, Carrondo MJT. Viruses and virus-like particles in biotechnology: Fundamentals and applications. Compr Biotechnol 2019:633-56. Doi:10.1016/B978-0-12-809633-8.09046-4.

124. Swann H, Sharma A, Preece B, et al. Minimal system for assembly of SARS-CoV-2 virus like particles. Sci Rep 2020;10(1):1-5. Doi:10.1038/ s41598-020-78656-w.
125. Lai C-Y, To A, Ann T, et al. Recombinant protein subunit SARS-CoV-2 vaccines formulated with CoVaccine HT adjuvant induce broad, Th1 biased, humoral and cellular immune responses in mice. bioRxiv 2021:1-23.

126. Zhao J, Cui W, Tian BP. The Potential Intermediate Hosts for SARS-CoV-2. Front Microbiol 2020;11:1-11. Doi:10.3389/fmicb.2020.580137.

127. Johansen MD, Irving A, MontagutelliX, et al. Animal and translational models of SARS-CoV-2 infection and COVID-19. Mucosal Immunol 2020;13(6):87791. Doi:10.1038/s41385-020-00340-z.

128. Rosenke K, Meade-White K, Letko M, et al. Defining the Syrian hamster as a highly susceptible preclinical model for SARS-CoV-2 infection. bioRXiv 2020:1-35. Doi:10.1101/2020.09.25.314070.

129. Imai M, Iwatsuki-Horimoto K, Hatta M, et al. Syrian hamsters as a small animal model for SARS-CoV-2 infection and countermeasure development. Proc Natl Acad Sci USA 2020;117(28):16587-95. Doi:10.1073/pnas.2009799117.

130. Mathavarajah S, Dellaire G. Lions, tigers and kittens too: ACE2 and susceptibility to COVID-19. Evol Med Public Heal 2020;2020(1):10913. Doi:10.1093/EMPH/EOAA021.

131. Costagliola A, Liguori G, D'angelo D, Costa C, Ciani F, Giordano A. Do animals play a role in the transmission of severe acute respiratory syndrome coronavirus-2 (SARS-CoV-2)? a commentary. Animals 2021;11(1):1-11. Doi:10.3390/ani11010016.

132. Brand V den, Leijten haagmans L, Riel V, Martina. Pathology of Experimental SARS Coronavirus Infection in. Vet Pathol 2008;562:551-62.

133. Belser JA, Katz JM, Tumpey TM. The ferret as a model organism to study influenza A virus infection. DMM Dis Model Mech 2011;4(5):5759. Doi:10.1242/dmm.007823.

134. Kim Y II, Kim SG, Kim SM, et al. Infection and Rapid Transmission of SARS-CoV-2 in Ferrets. Cell Host Microbe 2020;27(5):704-9.e2. Doi:10.1016/j.chom.2020.03.023.

135. Saini KS, Lanza C, Romano M, et al. Repurposing anticancer drugs for COVID-19-induced inflammation, immune dysfunction, and coagulopathy. Br J Cancer 2020;123(5):694-7. Doi:10.1038/s41416-020-0948-X.

136. Derosa L, Melenotte C, Griscelli F, et al. The immuno-oncological challenge of COVID-19. Nat Cancer 2020;1:946-64. Doi:10.1038/s43018-020-00122-3.

137. Greten FR, Grivennikov SI. Inflammation and Cancer: Triggers, Mechanisms, and Consequenc- 
es. Immunity 2019;51(1):27-41. Doi:10.1016/j. immuni.2019.06.025.

138. Feng $H$, Wei $X$, Pang $L$, et al. Prognostic and Immunological Value of Angiotensin-Converting Enzyme 2 in Pan-Cancer 2020;7:1-13. Doi:10.3389/fmolb.2020.00189.

139. van Dam PA, Huizing $M$, Mestach $G$, et al. SARS-CoV-2 and cancer: Are they really partners in crime? Cancer Treat Rev 2020;89:1-10. Doi:10.1016/j.ctrv.2020.102068.

140. Pentimalli F. Covid-19 still on center stage. Ann Res Oncol 2021;1(2):98-100. Doi:10.48286/ aro.2021.11.

141. The Lancet Oncology. COVID-19 and cancer: 1 year on. Lancet Oncol 2021;22(4):411. Doi:10.1016/S1470-2045(21)00148-0.

142. Fratino L, Serraino D. SARS-CoV-2 and Oncology. Ann Oncol Res 2021;1(2):101-4.

143. Ranganathan P, Sengar M, Chinnaswamy G, et al. Impact of COVID-19 on cancer care in India: a cohort study. Lancet Oncol 2021;2045(21):1-7. Doi:10.1016/s1470-2045(21)00240-0.

144. Lee KJ, Rieth EF, Mapes R, Tchoudovskaia A V., Fischer GW, Tollinche LE. COVID-19 in the Cancer Patient. Anesth Analg 2020;131(1):16-23. Doi:10.1213/ANE.0000000000004884.

145. Venkatesulu BP, Mallick S, Lin SH, Krishnan S. A systematic review of the influence of radiation-induced lymphopenia on survival outcomes in solid tumors. Crit Rev Oncol Hematol 2018;123:4251. Doi:10.1016/j.critrevonc.2018.01.003.

146. Bora VR, Patel BM. The Deadly Duo of COVID-19 and Cancer! Front Mol Biosci. 2021;8:112. Doi:10.3389/fmolb.2021.643004.

147. Lee AJX, Purshouse K. COVID-19 and cancer registries: learning from the first peak of the SARSCoV-2 pandemic. Br J Cancer 2021;124(11):177784. Doi:10.1038/s41416-021-01324-x.

148. Dai M, Liu D, Liu M, et al. Patients with cancer appear more vulnerable to SARS-CoV-2: A multicenter study during the COVID-19 outbreak. Cancer Discov 2020;10(6):783-91. Doi:10.1158/2159-8290.CD-20-0422.

149. Health G.A Practical Approach to the Management of Cancer Patients During the Novel Coronavirus Disease 2019 ( COVID-19 ) Pandemic: An International Collaborative Group. 2020;2019:936-45. Doi:10.1634/theoncologist.2020-0213.

150. Cancer | COVID-19 Treatment Guidelines. Available from: https://www.covid19treatmentguidelines.nih.gov/special-populations/ cancer/. Last accessed: Feb 23, 2022.
151. Khorana AA, Francis CW, Culakova E, Kuderer NM, Lyman GH. Thromboembolism is a leading cause of death in cancer patients receiving outpatient chemotherapy.JThromb Haemost 2007;5(3):6324. Doi:10.1111/j.1538-7836.2007.02374.x.

152. Jee $H$, Nwagwu C, Anyim O, Ekweremadu C, Kim S. International Immunopharmacology COVID-19 and cancer: From basic mechanisms to vaccine development using nanotechnology. Int Immunopharmacol 2021;90:1-11. Doi:10.1016/j.intimp.2020.107247.

153. Sallah S, Wan JY, Nguyen NP, Hanrahan LR, Sigounas G. Disseminated intravascular coagulation in solid tumors: Clinical and pathologic study. Thromb Haemost 2001;86(3):828-33. Doi:10.1055/s-0037-1616139.

154. Borcherding N, Jethava Y, Vikas P. Repurposing Anti-Cancer Drugs for COVID-19 Treatment. dove Press 2020;14:5045-58.

155. Derosa L, Melenotte C, Griscelli F, et al. The immuno-oncological challenge of COVID-19. Nat Cancer 2020;1(10):946-64. Doi:10.1038/ s43018-020-00122-3.

156.JainKK.PersonalizedImmuno-Oncology.MedPrinc Pract 2021;30(1):1-16. Doi:10.1159/000511107.

157. Liu C, ZhaoY, Okwan-Duodu D, Basho R, CuiX. COVID-19 in cancer patients: risk, clinical features, and management. Cancer Biol Med 2020;17(3):51927. Doi:10.20892/j.issn.2095-3941.2020.0289.

158. Cancerandsars-cov-2infection:Diagnosticandtherapeutic challenges. Cancers (Basel) 2020;12(6):117. Available from: http://www.embase.com/ search/results?subaction=viewrecord\&from=export\&id=L2004558182\%0Ahttp://dx.Doi. org/10.3390/cancers12061581. Last accessed: Feb 23, 2022.

159. Isgrò MA, Vitale MG, Celentano E, et al. Immunotherapy may protect cancer patients from SARS-CoV-2 infection: a single-center retrospective analysis. J Transl Med 2021;19(1):2-7. Doi:10.1186/s12967-021-02798-2.

160. KlenertD, FunkeF, Mattauch L, O'Callaghan B. Five Lessons from COVID-19 for Advancing Climate Change Mitigation. Environ Resour Econ 2020;76(4):751-78. Doi:10.1007/s10640-020-00453-w.

161. Manzanedo RD, Manning P. COVID-19: Lessons for the climate change emergency. Sci Total Environ 2020;742:1-4. Doi:10.1016/j.scitotenv.2020.140563.

162. Bellamy J. Lessons Learned from COVID-19 : Insights for Climate Change Mitigation. NAADSN 2020:1-12. 
163. Sultana J, Crisafulli S, Gabbay F, Lynn E, Shakir $S$, Trifirò G. Challenges for Drug Repurposing in the COVID-19 Pandemic Era. Front Pharmacol 2020;11:1-13. Doi:10.3389/fphar.2020.588654.
164. Mahdy MAA, Younis W, Ewaida Z. An Overview of SARS-CoV-2 and Animal Infection. Front Vet Sci 2020;7:1-12. Doi:10.3389/ fvets.2020.596391. 